\title{
Factors of tooth extraction among adult patients attending in exodontia depart- ment of Dhaka Dental College and Hospital
}

\author{
Nasreen $T^{1}$ and Haq $M E^{2}$
}

\begin{abstract}
:
In the management of the adult dental patient efforts are geared towards the preservation of permanent dentition as it is important for maintaining normal occlusal relationship, play role in aesthesis, speech, influence food habit and nutrition. This hospital based descriptive type of cross sectional study was done at Exodontia Department of Dhaka Dental College and Hospital to identify the factors that contribute in tooth extraction among the respondents. The study was carried out during the month of January to June 2009 and 110 respondents selected purposively. The study showed the majority of the respondents $(57.3 \%)$ were in the age group of $20-39$ years. Their mean age was 36.85 .years, SD of age was \pm 13.85 and age range was $15-85$ years. Among the respondents $46.4 \%$ were male and $53.6 \%$ were female. Dental caries was the leading cause of tooth extractions in $68 \%$ cases. It was also observed that post filling complication contributed in $33 \%$ cases of extraction. Patient requests due to economic cause in $16 \%$ cases, negligence in $11 \%$ cases and even distance of the treatment centre from residence reported in $15 \%$ cases. The treatment philosophy of the centre played a vital role. Heavy rush of the patient and inconvenient conservative treatment schedule caused many unnecessary extractions. (Ban J Orthod and Dentofac Orthop, Oct 2011; Vol-2, No. 1, p 7-10)
\end{abstract}

\section{INTRODUCTION}

The sequel of tooth loss in the patient may be particularly harmful, leading to drifting, tilting which may lead to further complication like caries, periodontitis and even orthodontic and tempomandibular joint problem. ${ }^{1}$ Tooth preservation is very important to reduce the tendecies for extraction, which may cause unnecessary pain and dental fear. ${ }^{2}$ When aesthetics is impaired as a result of tooth loss, further complications could arise such as psychological stress, disturbances in social interaction including peer group acceptance, and the development of negative self-esteem. ${ }^{3}$ The cost of correcting and managing these complications may further be a burden to the patient. ${ }^{4}$

Many studies have identified disease factors such as caries, periodontal disease, and trauma as major causes of tooth loss among adults. However, there are also non-disease factors that are highly contributory to tooth mortality. ${ }^{5}$ These include ignorance, personal dental belief, ${ }^{6}$ socio-economic and cultural factors. For example, in some parts of Africa teeth are deliberately removed for ritual and traditional purposes. Among Nigerian tribes, the practice of deciduous canine (usually the mandible) germinectomy is believed to guard against symptoms such as high fever, which may be associated with teething in children. ${ }^{7}$ Despite the fact one of the main thrusts of the practice of dentistry is to preserve the teeth, there are always judicious reasons for tooth loss. This includes planned orthodontic and prosthetic treatment. ${ }^{8}$

A lot of socio-economic changes have since taken place in the country among which is the increase in specialization and fields of medical practice in the country. But changes have not occurred in the pattern of service provision for oral health care and in the oral hygiene status. We need changes which will include the increased incorporation of oral health care services to the primary, secondary and tertiary levels of health care delivery sys- tems and the improvement in the knowledge, attitude, and practices of the general population in terms of nutrition, oral hygiene, and health care seeking behavior. The present study is to find out the factors that are playing behind in the pattern of tooth extraction in a tertiary referral centre.

\section{BACKGROUND}

Tooth mortality, which is mainly a reflection of untreated dental caries and periodontal disease, is considered as a crude but useful measure for the dental status of a community. ${ }^{9}$ Factors of tooth extraction had large geographical and cultural differences between various countries. Caries is the main cause of tooth loss in large number countries. ${ }^{10}$ Periodontal diseases are the main cause of dental extractions in India. In several countries, Caries and periodontal disease seem to cause almost equal percentage of tooth as is in the United States of America. ${ }^{11}$

Actually During the past decades rapid changes have occurred in the distribution of oral diseases worldwide. Traditionally, the prevalence of dental caries was high in most industrialized countries while low caries levels have been observed in developing countries. ${ }^{12}$ For both children and adults of western industrialized countries significant improvements in oral health status are now noted with the changing patterns of sugar consumption, improved oral hygiene, effective use of fluorides, changing lifestyles and standards of living, establishment of school based preventive programmers, and effective use of oral health services. In developing countries like Bangladesh, changing living conditions due to urbanization and adoption of western lifestyles are often considered potential risk factors for the incidence of dental caries. ${ }^{13}$

It is important to bear in mind that the extraction of teeth is not only based on disease related factors. Studies in Scotland, the

\footnotetext{
${ }^{1}$ Dental surgeon, In charge of orthodontics and dentofacial orthopedic department, Dhaka Dental College and Hospital, Dhaka, Bangladesh.

${ }^{2}$ Professor and Head department of Orthodontics, City Dental College and Hospital, Dhaka, Bangladesh.
} 
Netherlands and the USA have shown that the decision to extract a tooth is substantially influenced by factors related to both the patient's and the dentist's specific requirements. These factors may include the dentist's philosophy of practice, his experience as well as esthetic, prosthetic and economic considerations. These factors may have played an important role in the decision for tooth extraction. ${ }^{14}$

In Bangladesh, where treatment facilities are very limited, poor oral health has turned into a big medical and social problem. Poverty, ignorance, prejudice, malnutrition, low socioeconomic status, adverse traditional attitude and practice and lack of medical facilities contributed to poor dental health care behavior. Most of the people visit to dentist when conservative treatment is difficult to do. The practices of quack and the use of many indigenous methods to get relief from diseases also place them at high risk of complications. The over all influence of oro-dental disease upon the whole community is very severe and can not be overlooked as it plays an adverse role on general health. ${ }^{15-17}$

\section{PATIENTS AND METHODS}

Study site : Department of Oral and Maxillo Facial Surgery, Dhaka Dental College Hospital. It deals with the primary dental care services of Dhaka city and referral center for patients with dental problems from throughout Bangladesh.

Study population : The patients of 15-85 years old attending in Department of Oral and Maxillo Facial Surgery, diagnosed by general out patient department were the study population.

Study design : This was a hospital based descriptive type of cross-sectional study

Study period : Study period was six months (January 2009 to June 2009).

Sample size : 110 patients attending Department of Oral and Maxillo Facial Surgery, were taken purposively.

Data collection instrument : A semi-structured questionnaire was used as data collection instrument. Pre-testing of the research instrument was done.

Data collection technique : Data were collected by interviewing and examining the patients. The examination of tooth, gums and tongue, oral mucosa and tonsils was carried out in a normal chair with the help of a flash light.

Data analysis : The collected data were checked, verified and edited daily. After proper verification, the data were entered into computer by using software SPSS Win Version 11.5. After the entry, range and consistency of data were checked. Data were analyzed according to the objectives of the study.

\section{RESULTS}

Over a period of six months, 110 patients also needed tooth extraction had been interviewed and examined. Mean age of the

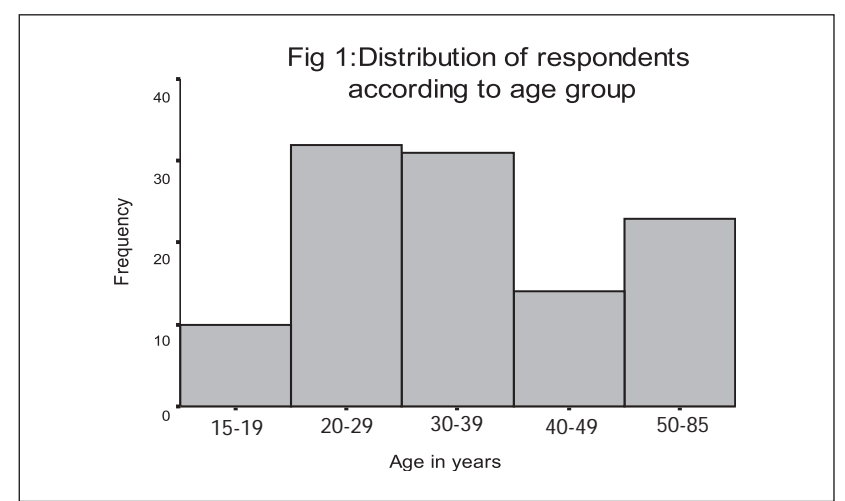

patients was $36.85 \pm 13.85$ years (range: $15-85$ years)[Fig 1].

Among the respondents 51 (46.4\%) were male and 59 (53.6\%) were female. The education level of most of the respondents is up to primary $(30.9 \%)$, followed by illiterate $(25.5 \%)$, higher secondary $(15.5 \%)$, secondary $(13.6 \%)$, graduation $(8.2 \%)$ and post graduate $(6.4 \%)$. Most of the respondents attending the dental college are house wife $(38.2 \%)$ followed by service holder (20.9\%), daily worker $(12.7 \%)$ and business man (11.8\%). Most of the respondents $(46.36 \%)$ belong to the 5000-10000 taka monthly family income group. Caries $(68.2 \%)$ was the leading cause of tooth extraction followed by pericoronitis (14.5\%), periodontitis $(12.7 \%)$ and Orthodontic treatment includes in other causes of tooth extraction (4.5\%) [Fig 2].

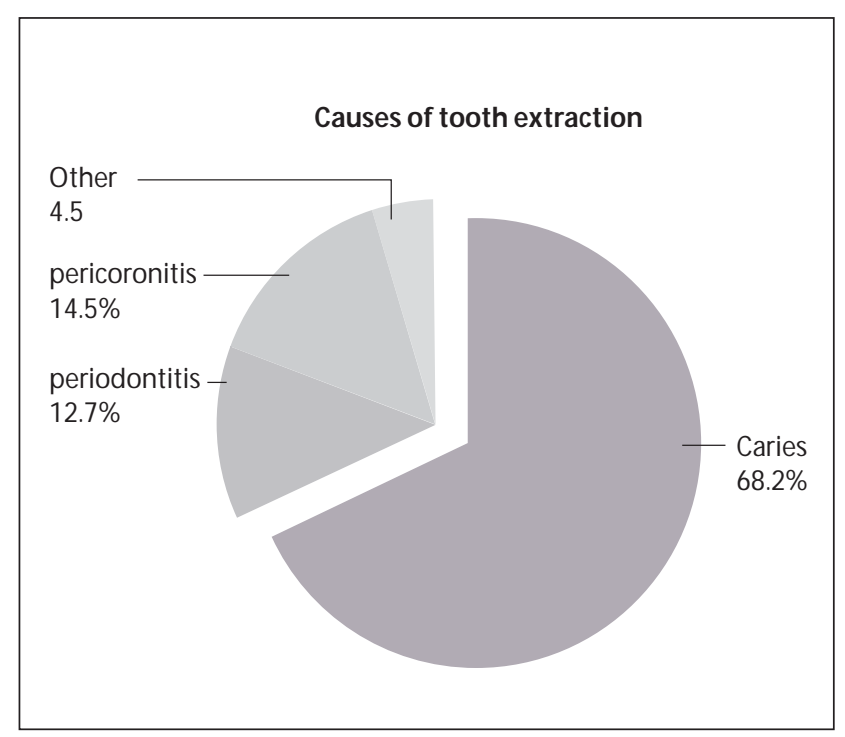

In $29.1 \%$ cases patient suffered other oral disease like gingivitis, periodontitis and apthus ulcer. There was no obvious difference among the respondents in terms of previous tooth extraction $(52.7 \%)$ and new cases $(47.3 \%)$. Negligible number of patients $(6.4 \%)$ took conservative management earlier in comparison to no intervention (93.6\%). No notable difference between loss tooth in upper jaw (48.2\%) and lower jaw (45.2\%) and only a few patients $(6.4 \%)$ had history of tooth loss in both jaws [Table $1]$.

8

Bangladesh Journal of Orthodontics and Dentofacial Orthopedics (BJO and DFO)

Vol. 2, No. 1, October 2011 
Table 1: Type of tooth extraction

\begin{tabular}{lll}
\hline Type of tooth extraction & Frequency & Percent \\
\hline Maxillary & 53 & 48.1 \\
Mandibular & 50 & 45.5 \\
Both & 7 & 6.4 \\
Total & 110 & 100.0 \\
\hline
\end{tabular}

Most respondents (56.4\%) did not visit doctor prior to their present visit and (29.1\%) patient got advised to conserve their teeth. Causes of patient's request for tooth extraction were mainly due to post filling complication (33\%), economic (16\%), negligence $(16 \%)$, distance $(11 \%)$ and other causes like peer pressure, personal belief etc (24\%) [Fig 3].

\section{Fig 3 :Canses of patierl"s Isquest fis two the extractio}
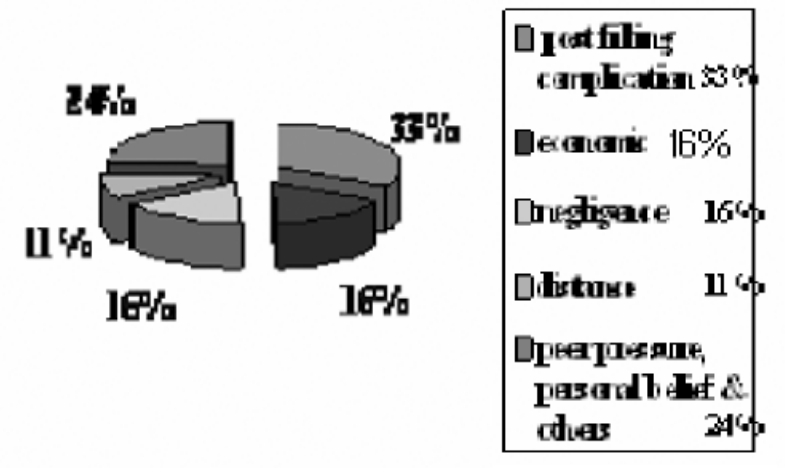

Most of the respondents $96.4 \%$ clean their tooth regularly in comparison to only $3.6 \%$ not clean their tooth regularly. Tooth paste $(82.7 \%)$ was preferred for tooth cleaning followed by coal $(10 \%)$, tooth power $(6.4 \%)$ and others $(.9 \%)$. Respondents use brush $(83.6 \%)$ for cleaning tooth followed by finger $(14.5 \%)$ and others $(1.8 \%)$. Carious tooth present in among $66 \%$ respondents and $45 \%$ have more than one carious tooth. $52 \%$ respondents had prior missing tooth and $23 \%$ had more than one missing tooth. Only $6 \%$ patient had earlier conservative treatment in comparison to $94 \%$ had none. Majority of the respondents (69.1\%) have no habit of taking cold drinks in comparison to taking cold drinks $(30.9 \%)$. Only $23.6 \%$ of the respondents had habit of taking fast food, $17.3 \%$ had the habits of taking tobacco, $22.7 \%$ took betel leaf and $67.3 \%$ had the habit of taking sweet.

\section{DISCUSSION}

In this study we found that more than half of the teeth (68.2\%) of the respondents were extracted due to caries. This result is similar to the study that was previously done in Dhaka Dental College and Hospital. ${ }^{17}$
This result is also similar to those of some European and Asian countries. ${ }^{6}$ But it differs from an Indian study ${ }^{18}$. These differences should be viewed with caution since some of the studies reported the reason for extraction considering only the permanent teeth; others considered both permanent and primary dentition.

The majority of studies have reported caries to be the main reason for overall tooth loss. Some studies reported that periodontal disease was the main reason, while others found that caries and periodontal disease were equally responsible. ${ }^{14}$ Furthermore, although the majority of these studies reported periodontal disease to account for the majority of tooth extractions in older patients, some reported caries as the main reason for tooth loss in all ages.

A notable feature of the results was found that $29.1 \%$ of all extractions occurred in the age-group 20-29 years and 28.2\% of all extraction occurred in the age group 30-39 years. The cause of this high tooth mortality rate during this part of life is, without a doubt, the high incidence of dental caries. It is comparable with a Kuwaiti study where $70 \%$ tooth extracted due to caries in 21 30 years age-group and $61.1 \%$ in $31-40$ years age-group. ${ }^{6}$ It also corresponds with a Jordanian study where extensive caries was predominant reason given for extraction. ${ }^{19}$

In the study it is found that $64.5 \%$ of the respondents are suffering from dental caries. But only $6.4 \%$ had taken any conservative treatment. The missing tooth is present among $52.7 \%$ respondents. This indicates poor health care seeking behavior. It is very interesting to notice that $70.9 \%$ cases were not advised or suggested to conserve their tooth by the attending doctor. This data indicates the treatment philosophy of the center and the surgeons concerned. It may be due to limited conservative facilities of the center, shortage of man power, patient burden, time limitation etc.

In the study $29.1 \%$ patients were suffering from other diseases. Gingivitis $(23.6 \%)$ is the leading oral health problem followed by periodontitis $(4.5 \%)$ and aphthus ulcer $(2.7 \%)$. There is no significant difference in upper and lower jaw tooth extraction. Maxillary tooth $(48.2 \%)$ and mandibular tooth is $(45.5 \%)$. The study showed that $53.6 \%$ respondents were female and $46.4 \%$ were male. Most of the patients were housewife (38.2\%) and service holders $(20.9 \%)$.

It is noticeable that only $36.4 \%$ respondents believe that earlier visit could be beneficial for their tooth conservation. Whereas $58.2 \%$ think that tooth extraction would not cause any future health problem. Among these respondents $25.5 \%$ were illiterate, $30.9 \%$ had primary education, $13.6 \%$ had secondary education, $15.5 \%$ had higher secondary education and others had graduation and above.

The study has special focus on the treatment philosophy of the centre and as well as dental and oral health care behavior of the patients. 


\section{CONCLUSION}

This cross sectional study done in Dhaka Dental College and Hospital to find out the factors which play in tooth extraction among adult patients concludes that tooth extraction is occurring due to multifactor reasons. Among the dental diseases caries is the main culprit to cause tooth extraction. Ignorance, economic constraint and inconvenient conservative treatment are vital issues to concern. Greater consideration should be taken to increase peoples awerness and knowledge of their own dental health and changed of their attitude and behaviour in relation to oral health care.

\section{REFERENCE}

1. Morenike OF, Olayinka DO, Temitope AE et al. Pattern of Dental Extraction in Children in a Nigerian Tertiary Hospital. Journal of Contemporary Dental Practice, Volume 6, No. 2, May 15, 2005

2. Ong G, Yeo JF, Bhole S. A survey of reasons for extraction of permanent teeth in Singapore. Community Dent Oral Epidemiol. 1996 Apr;24(2):124-7.

3. Zadik Y, Sandler V, Bechor R, Salehrabi R. Analysis of factors related to extraction of endodontically treated teeth. Oral Surg Oral Med Oral Pathol Oral Radiol Endod. 2008 Nov;106(5):e31-5. Epub 2008 Aug 20.

4. Adeyemo WL, Oderinu HO, Oluseye SB, Taiwo OA, Akinwande $J A$. Indications for extraction of permanent teeth in a Nigerian teaching hospital: a 16-year follow-up study. Nig Q J Hosp Med. 2008 Jul-Sep;18(3):128-32.

5. Jovino-Silveira RC, Caldas Ade F Jr, de Souza EH, Gusmão ES Primary reason for tooth extraction in a Brazilian adult population. Oral Health Prev Dent. 2005;3(3):151-7.

6. Al-Shammari KF, Al-Ansari JM, Al-Melh MA, Al-Khabbaz AK. Reasons for tooth extraction in Kuwait. Med Princ Pract. 2006;15(6):417-22.
7. Hull PS, Worthington HV, Clerehugh V, Tsirba R, Davies RM, Clarkson JE. The reasons for tooth extractions in adults and their validation. J. Dent. 1997 May-Jul;25(3-4):233-7.

8. Corbet EF, Davies WI. Reasons given for tooth extraction in Hong Kong. Community Dent Health. 1991 Jul;8(2):121-30.

9. Jamila M. A. Farsi, DDS, PhD. The common causes of extraction of teeth in Saudi arabiaThe Saudi Dental Journal, Volume 4, Number 3, September 1992

10. Coxhead JL. Reasons for extraction in general practice. New Zealand Dent Fluoridation 1960;56:182-183.

11. American Dental Association survey of needs for dental care, Bureau of Economic Research and Statistics. Am Dent Assoc, Chicago, 1965.

12. Johansen SB, Johansen JR. A Survey of causes of permanent tooth extractions in South Australia. Aust Dent J 1977;22:238-42.

13. Akhter R, Hassan NM, Aida J, Zaman KU, Morita M. Risk indicators for tooth loss due to caries and periodontal disease in recipients of free dental treatment in an adult population in Bangladesh. Oral Health Prev Dent. 2008;6(3):199-207.

14. Murray H, Locker D, Kay EJ. Patterns of and reasons for tooth extractions in general dental practice in Ontario, Canada. Community Dent Oral Epidemiol. 1996 Jun;24(3):196-200.

15. Ainamo J, Sarkki L, Kuhalampi ML, Palolampi L, Piirto O. Frequency of periodontal extractions in Finland. Comm Dent Health 1984;1:165-72.

16. Kay EJ, Blinkhorn AS. The reasons underlying the extraction of teeth in Scotland. Br Dent J 1986;160:287-90.

17. Banik AK. Reasons for extraction of permanent teeth in Dhaka Dental College Hospital: A statical study. Bangladesh Dent J. 1998;14:34-37.

18. Mehta FS, Sanjara MK, Shroff BC. Analysis of periodontal disease as a cause of tooth loss. J Indian Dent Assoc 1960;32:71-6.

19. Al-Sharafat FS, Al-Negrish AR. Reasons for extraction of teeth in central region of Jordan. Pak Oral Dental J. 2005;28(2):233-36.

\section{Correspondence :}

\section{Dr. Tania Nasreen BDS, MPH}

Dental Surgeon

Dept. of Orthodontics and Dentofacial Orthopedics

Dhaka Dental College and Hospital

Mirpur 14, Dhaka 1206

Mobile : +8801711147951, E-mail : Tania1613@yahoo.com 